\title{
DA GUINÉ-BISSAU AO BRASIL: IMPACTOS DA INSTABILIDADE POLÍTICA NA MANUTENÇÃO DOS PRINCÍPIOS CONSTITUCIONAIS PARA A EDUCAÇÃO
}

\author{
Maria RehDeR ${ }^{1}$ (1) \\ RUI DA SILVA 2 \\ Talismá Nice Fero Gomes Dias da Silva Monteiro 30
}

\begin{abstract}
RESUMO: $\mathrm{O}$ artigo buscou trazer uma reflexão comparada sobre os impactos da instabilidade política (com a transiçáo não democrática de governos) na manutenção dos princípios constitucionais para o direito à educação na Guiné-Bissau e no Brasil. A partir da análise documental de educação e de entrevistas semiestruturadas com dois estudantes, uma mesma consequência foi constatada: impactos nos investimentos públicos alocados para os setores sociais. Na Guiné-Bissau, o golpe de 2012 foi marcado pela elevada ajuda internacional à governança e segurança em detrimento à educaçáo, desafiando a Lei de Bases do Sistema Educativo e o Plano Setorial da Educaçáo. No Brasil, após o impeachment de Dilma Rousseff em 2016, foi aprovada a Emenda Constitucional 95 que congela em 20 anos os gastos públicos em educação, inviabilizando o Plano Nacional de Educação.
\end{abstract}

Palavras-chave: Educação. Direitos. Brasil. Guiné-Bissau.

\section{FROM GUINEA-BISSAU TO BRAZIL: IMPACTS OF POLITICAL INSTABILITY ON MAINTAINING CONSTITUTIONAL PRINCIPLES FOR EDUCATION}

\begin{abstract}
The article aims to bring a comparative reflection on the impacts of political instability (with the non-democratic transition of governments) on maintaining the constitutional principles for the right to education in Guinea Bissau and Brazil. From the documentary analysis on education and semi-structured interviews with two students, the same consequence is verified: impacts on public investments to social sectors. In Guinea-Bissau, the 2012 coup was marked by high international aid to governance and security over education, challenging the Basic Law of the Education System and Education Sector Plan. In Brazil, after
\end{abstract}

\footnotetext{
${ }^{1}$ Universidade Estadual de Campinas, Grupo de Estudos e Pesquisas em Política Educacional Campinas (SP), Brasil. E-mail: maria.rehdersp@gmail.com

${ }^{2}$ Universidade do Porto, Centro de Estudos Africanos - Porto, Portugal. E-mail: rdasilva.email@gmail.com ${ }^{3}$ Universidade de Lisboa, Instituto de Educação - Lisboa, Portugal. E-mail: talisma.dias@gmail.com DOI: 10.1590/ES0101-73302018201813
} 
Rousseff's impeachment in 2016, Constitutional Amendment 95 was approved, which freezes public spending on education in 20 years, rendering the National Education Plan unfeasible.

Keywords: Education. Rights. Brazil. Guinea-Bissau.

\section{DE LA GUINÉE-BISSAU AU BRÉSIL : IMPACTS DE L'INSTABILITÉ POLITIQUE SUR LE MAINTIEN DES PRINCIPES CONSTITUTIONNELS DE L'ÉDUCATION}

RESSUÉ:Cette article apporte une réflexion comparative sur les impacts de l'instabilité politique (resultat de la transition non démocratique des gouvernements) sur le maintien des principes constitutionnels du droit à l'éducation en Guinée Bissau et au Brésil. À partir d'une analyse documentaire sur l'éducation et des entretiens semi-structurés avec deux étudiants, la même conséquence est vérifiée: les impacts sur les investissements publics alloués aux secteurs sociaux. En Guinée-Bissau, le coup d'État de 2012 a été marqué par une aide internationale élevée à la gouvernance et à la sécurité de l'éducation, remettant en question le droit fondamental du système éducatif et le plan sectoriel de l'éducation. Au Brésil, après la destitution de Rousseff en 2016, l'amendement constitutionnel 95, qui gèle les dépenses publiques d'éducation en 20 ans, a été approuvé, en rendant le plan national d'éducation irréalisable.

Mots-clés : Education. Droits. Brésil. Guinée-Bissau.

\section{Introdução}

I

nseridos em diferentes contextos geopolíticos e socioeconômicos, a Guiné-Bissau e o Brasil são os países escolhidos para a realização da análise comparada, que aqui se apresenta, sobre os impactos da instabilidade política (com a transição não democrática de governos) na efetivação de suas constituiçóes - conjunto de normas e leis que regem um país cuja efetividade é fundamental para o acesso de todas e todos aos direitos sociais, especialmente à educação. Esse texto foi escrito no ano em que se completa 30 anos da Constituiçáo Federal de 1988 no Brasil, com o objetivo de trazer uma contribuição internacional a partir da análise de um contexto estrangeiro de instabilidade política, no caso a Guiné-Bissau, cuja carta magna é a Constituição da República da Guiné-Bissau de 1996, suspensa de 2012 a 2014 devido ao último Golpe de Estado de 2012 (CIA, 2018).

A Guiné-Bissau foi escolhida pelo fato de as autoras e o autor deste artigo, uma guineense, uma brasileira e um português, já terem realizado pesquisas 
acadêmicas e trabalhos in loco em educação no país, constatando impactos da instabilidade política na efetivação do direito à educação de crianças e adolescentes. Também por acreditarem na hipótese de que reflexóes comparadas entre Brasil e países cujo direito à educação é desafiado devido às consequências da instabilidade política (com transiçôes não democráticas de governo) podem trazer importante contribuição para a academia brasileira, principalmente no período pós-impeachment de Dilma Rousseff.

Sobre o Brasil, destaca-se que com a mudança abrupta de presidente em 2016, com a ascensão do governo de Michel Temer, o país tem sofrido medidas arbitrárias que propóem alterações estruturantes na educação. Entre elas, a partir de uma medida provisória (que consiste em um ato unipessoal do Presidente da República e possui força imediata de lei), Temer sancionou a Reforma do Ensino Médio em Lei $n^{\circ} 13.415$ de 16 de fevereiro de 2017. Entre os problemas, destaca-se a desvalorização do professor por meio da legitimação da figura do "notório saber" sendo regulamentado para atuar nas escolas de ensino médio (CARRANO, 2017).

Entretanto, essa não foi medida isolada. Esse artigo destaca um dos impactos mais negativos pós-impeachment de Rousseff: a aprovação da Emenda Constitucional no 95 (BRASIL, 2016), que congela em 20 anos os gastos públicos em educação em um país cujo número de crianças e adolescentes em exclusão escolar é maior do que a população da Guiné-Bissau (cerca de 2,5 milhóes de pessoas com idade entre 4 e 17 anos, 1,5 milhão deles fora do ensino médio).

Sobre a lusófona Guiné-Bissau, localizada na África Ocidental, cuja expectativa de vida náo ultrapassa os 56 anos, destaca-se que, apesar do pequeno território em terra e populaçáo quando comparada ao Brasil, com mais de $28.000 \mathrm{~km}^{2}$ - semelhante ao estado de Alagoas — e com 1,8 milhão de habitantes, o país vive grandes desafios de desenvolvimento e direitos humanos, com a sua carta magna diariamente colocada em xeque (BARROS, 2012). O país é experiente em transiçóes e descontinuidade de políticas públicas desde a sua independência (SOUSA, 2012).

De 1998 a 2013, a Guiné-Bissau teve dez primeiros-ministros, eleitos sem terminar mandato, quatro chefes de Estado-Maior, todos afastados por levantamentos militares (dois foram assassinados em funçóes pelos militares) sem completar o mandato, e três presidentes da república e três presidentes interinos, designados em virtude das sublevaçóes militares (MENDES, 2013, p. 2).

O narcotráfico tem aumentado devido à falta de controle e de um estado de direito fortalecido (O’REGAN \& THOMPSON, 2013). O último golpe isolou o país no plano internacional, incluindo sançóes da União Africana, que suspendeu a Guiné-Bissau como membro, além das Nações Unidas e a União Europeia, que adotaram medidas restritivas individuais contra militares devido à sua participação no golpe (MENDES, 2013, p. 2). Os impactos na educação 
foram sentidos com a interrupção de aulas, sem concluir calendário escolar e com professores em greve devido ao não pagamento de salários.

\section{Metodologia}

A abordagem metodológica para a realização da análise comparada foi qualitativa (interpretativa), tendo em conta a problemática e a natureza do objeto. Recorremos à análise documental (de documentos primários) e foi valorizada a voz de sujeitos de direitos dos dois países a partir da análise de entrevistas semiestruturadas com dois adolescentes ativistas pelo direito à educaçáo já disponibilizadas em estudos e artigos anteriores. Os documentos utilizados podem ser caracterizados como dados pré-existentes e foram selecionados após uma análise exaustiva de documentos nos dois países como textos constitucionais, leis nacionais sobre educação, pesquisas, estudos e relatórios.

A reflexão a partir de análise comparada tem por referência os pressupostos inerentes à educação internacional e comparada (PHILLIPS \& SCHWEISFURTH, 2014; CROSSLEY \& WATSON, 2003). Apesar de uma definição ser problemática, uma vez que pode ser interpretada de diferentes formas, podemos considerar que consiste na aplicação de um conjunto alargado de corrente epistemológica, métodos, técnicas e teorias que servem de ponte para outras culturas e tradições, permitindo a compreensão de fenômenos educacionais entre locais e em outros locais (PHILLIPS \& SCHWEISFURTH, 2014; CROSSLEY \& WATSON, 2003).

O presente artigo levou em consideração, também, as seguintes dimensões éticas inerentes ao processo de investigação em educaçáo com base em vários autores (ROBSON, 2011; COHEN; MANION; MORRISON, 2009; BERA, 2016): compromisso de respeito pelas pessoas em suas diversidades, pelo conhecimento, pelos valores democráticos, pela justiça e equidade; qualidade da investigação em educação; e liberdade acadêmica. Com base nessa matriz destacamos, ainda, o consentimento informado e a realização de todos os esforços para manter a integridade e a autonomia e a não seleção apenas dos dados que são convenientes ao presente estudo.

O olhar comparado do Brasil com a Guiné-Bissau tem como motivaçáo o arcabouço teórico de Cartas à Guiné-Bissau, de Paulo Freire (FREIRE, 1977), cuja vivência no país foi fundamental para a produção do seu legado teórico, principalmente a sua inspiração com Amilcar Cabral, sendo "dois teóricos-ativistas, cujas convergências se deram na 'precedência da prática sobre a teoria; a importância da leitura da realidade cotidiana, como forma de apreensão do conhecimento válido e legítimo"” (GADOTTI \& ROMÃO, 2012, p. 32).

A educação, nesse artigo, é analisada como prática social na perspectiva emancipadora de Paulo Freire (1977, p. 20): 
Amilcar Cabral sabia que os canhóes sozinhos não faziam a guerra e que esta se resolve, em seu processo, a debilidade dos oprimidos se faz força, capaz de transformar a força dos opressores em fraqueza. Daí a preocupaçáo constante, a paciente impaciência com que invariavelmente se deu a formação política e ideológica dos militantes, qualquer que fosse o nível ou setor de sua ação. Daí a atenção especial que dedicou aos trabalhos de educação nas zonas libertadas e também com o carinho que, antes de ir à frente do combate, visitava as crianças das escolinhas e compartia com elas de seus jogos e de seus brinquedos e a quem sempre tinha uma palavra correta a dizer. Crianças a quem costumava a chamar de "flores de nossa revoluçáo".

Além de autores que trabalham a educaçáo na perspectiva dos direitos humanos (XIMENES, 2014; ARELARO, 2005; CURY, 2008), incluindo breve apresentação do contexto educacional e da legislação de educação frente aos desafios postos pela instabilidade.

\section{Guiné-Bissau: impactos na educação em números e contextos instáveis}

Quando analisamos o Índice Ibrahim da Governança na África, instrumento criado para o monitoramento da governança e políticas dos países africanos, verificamos que a Guiné-Bissau se encontra na posição 43 (de 54), com uma classificação de 41,3 (em 100), o mesmo que em 2011, antes do golpe de Estado mais recente (2012) e da crise político-institucional que se seguiu. A observação desse índice, no período de 2012 a 2103, mostra uma deterioração da classificação da global (38.1 em 2012 e 37.1 em 2013) e, consequentemente, de todos os indicadores - segurança e estado de direito; participação e direitos humanos; oportunidades econômicas sustentáveis; e desenvolvimento humano - fruto do agudizar da instabilidade vivida no país (MO IBRAHIM FOUNDATION, 2017).

A Guiné-Bissau é considerada o primeiro narco-Estado africano e um dos Estados mais frágeis do continente, vivendo um ambiente de crise alimentar e tendo sofrido um longo processo de fuga da população do meio rural para o meio urbano (O'REGAN \& THOMPSON, 2013; TEMUDO, 2008; TEMUDO \& ABRANTES, 2013; 2015). As condiçóes econômicas e sociais do país o colocam em uma situação de dependência de ajuda pública ao desenvolvimento, particularmente para os serviços públicos, desempenhando a sociedade civil - essencialmente as Organizaçóes Não-Governamentais (ONGs) e a Igreja Católica — papel crucial na assistência às populações e na consolidação do Estado, com destaque para os setores da educação, da saúde, dos direitos humanos, do ambiente e no processo de consolidação da paz (BARROS, 2012). 
Esse contexto de crise e fragilidade permanente levou as Naçóes Unidas, em 2009, a reformularem o seu mandato no país - de uma abordagem de desenvolvimento para uma de segurança - priorizando defesa, segurança e justiça (BARROS \& RIVERA, 2011). Todos esses fatores têm restringindo a efetivação do direito humano à educação, sendo que as escolas apresentam infraestrutura precária, sem alimentação e água. Mediante essa realidade de precariedade, a Organização das Naçóes Unidas para a Educação, a Ciência e a Cultura (UNESCO) chegou a cogitar a necessidade de reconstruçáo do sistema educativo:

"Por fim, tantas obras devem ser levadas a cabo para a escola de Guiné-Bissau que pode-se perguntar se o sistema educativo não é simplesmente para ser reconstruído em grande parte" (UNESCO, 2016).

Sem falar do elevado número de crianças e jovens que sequer chega às escolas em idade escolar: $28,1 \%$ das crianças estão em situação de exclusão, com maior prevalência para as meninas, e $40 \%$ dos adolescentes de 18 anos nunca frequentaram a escola (UNICEF, 2018). O sistema educativo herdado pelo colonialismo português foi sendo alterado desde a independência, com base nas experiências das zonas libertadas e por condicionalismos e exigências impostas do exterior, sendo esses últimos mais evidentes a partir da liberalização econômica e política iniciada em 1994 (CARR-HILL \& ROSENGART, 1982; 1983; PEHRSSON, 1996; MONTEIRO, 2005).

As características do sistema educativo da Guiné-Bissau, constituído em 1974, parecem ainda presentes, tendo sido aprovada a primeira e única Lei de Bases do Sistema Educativo apenas em 2010 (PEHRSSON, 1996; MONTEIRO, 2005; FURTADO, 2005; BARRETO, 2012; SILVA; SANTOS; PACHECO, 2015).

\section{Educação como direito assegurado na Carta Magna}

Apesar das melhorias alcançadas desde a independência, em um quadro de grande fragilidade e de ter havido um grande progresso no acesso, o sistema educativo ainda não chega a todas e todos guineenses não cumprindo, dessa forma, os desígnios da Constituição Guineense (GUINÉ-BISSAU, 1996) e da Lei de Bases do Sistema Educativo (GUINÉ-BISSAU, 2011a).

Após a independência, o direito humano à educação ficou expresso na sua Carta Magna de 1996:

A educação visa a formação do homem. Ela deverá manter-se estreitamente ligada ao trabalho produtivo, proporcionar a aquisição de qualificaçóes, conhecimentos e valores que permitam ao cidadão inserir-se na comunidade e contribuir para o seu incessante progresso (GUINÉ-BISSAU, 1996). 
Além de reconhecer a educação como via para formar cidadãos capazes de produzir valores e garantir o progresso nacional, nesse instrumento legal primário e nacional o Estado toma para si a responsabilidade da alfabetização universal: "O Estado considera a liquidaçáo do analfabetismo como uma tarefa fundamental" (GUINÉ-BISSAU, 1996). Assiste-se, também, a uma influência grande de organizaçôes internacionais (por exemplo o Fundo das Naçóes Unidas para a Infância UNICEF, a União Econômica e Monetária do Oeste Africano - UEMOA e o Banco Mundial) na promoção da educação para todos, que está alinhada com os desejos do Estado Guineense de forma a construir um Estado-nação moderno e que atinja o nível de progresso de outros países (SILVA; SANTOS; PACHECO, 2015).

Apesar de o princípio da universalidade do direito à educação e à igualdade de gênero estarem presentes na Guiné Bissau desde a luta pela libertação nacional (1964-1974) e a criação das primeiras escolas, onde já havia a promoção da gratuitidade e obrigatoriedade (CÁ, 2008; CHABAL, 2002), a educação como um direito universal está difícil de ser garantida até hoje.

Embora esses direitos tenham resultado em legislaçôes como Plano Nacional de Ação da Educação para Todos, 2003; Plano Setorial da Educação, 2009; Lei de Base do Sistema Educativo, 2010; Politica Nacional para a Igualdade e Equidade de Gênero, 2011; e a Carta da Política do Setor Educativo, 2015, até hoje não houve um desenvolvimento sustentado do setor, resultado da instabilidade desde a independência e da dependência de financiamento externo, pois esse último fator é a principal condição para ocorrerem intervençōes no sistema educativo (CARR-HILL \& ROSENGART, 1982; 1983; PEHRSSON, 1996; MONTEIRO, 2005; FURTADO, 2005).

Até hoje, mais de 40 anos após a independência, já tomaram posse 36 ministros da educação na Guiné-Bissau; as taxas de escolarização são as mais baixas do conjunto de países da África Ocidental; a taxa líquida de escolarização do $1^{\circ}$ ao $6^{\circ}$ ano de escolaridade é de $67 \%$; e há ausência generalizada de manuais escolares. Os professores em exercício são essencialmente do sexo masculino, com um elevado número sem formação pedagógica inicial e falta de acesso à formação contínua. A taxa de alfabetização (população com mais de 15 anos) é de 49,8\% (UNESCO, 2013; GUINÉ-BISSAU, 2011 a, UNICEF, 2018).

O sistema educativo mantém uma tendência elitista e urbana privilegiando o número de matrículas em detrimento da qualidade (CARR-HILL \& ROSENGART, 1982; 1983; PEHRSSON, 1996; MONTEIRO, 2005; FURTADO, 2005).

A Guiné-Bissau deverá por isso desenvolver bastantes esforços para, por um lado, assegurar-se de que todas as crianças beneficiam de um ciclo primário completo, mas por outro lado garantir que prosseguem os estudos até à conclusão do ensino básico. Esse desafio é imenso, sobretudo porque a estagnação verificada entre 2000 e 2010 evidencia dificuldades no sistema educativo para melhorar as suas performances (UNESCO, 2013, p. 11). 


\section{Brasil: Constituição Federal de 1988, a guardiã dos direitos sociais em risco}

A educação, direito de todos e dever do Estado e da família, será promovida e incentivada com a colaboração da sociedade, visando ao pleno desenvolvimento da pessoa, seu preparo para o exercício da cidadania e sua qualificação para o trabalho (BRASIL, 1988, art. 205).

No Brasil, a Constituição Federal de 1988

estabelece a educação como direito de todos e dever do Estado e declara como princípios do ensino não só a igualdade de condiçôes de acesso e permanência, mas a correspondente obrigação de oferta de uma escola com um padráo de qualidade que possibilite a todos os brasileiros e brasileiras - pobres ou ricos, do sul ou do norte, negro ou branco, homem ou mulher - cursarem uma escola com boas condiçóes de funcionamento e de competência educacional em termos de pessoal, material, recursos financeiros e projeto pedagógico que lhes permita identificar e reivindicar a "escola de qualidade comum" de direito de todos os cidadáos (ARELARO, 2005, p. 1040).

O direito à educação é compreendido pelos autores desse artigo a partir da visão de Cury sobre a educação básica: "Como direito, ela significa um recorte universalista próprio de uma cidadania ampliada e ansiosa por encontros e reencontros com uma democracia civil, social, política e cultural" (CURY 2008, p. 294).

Ainda sobre educação como um direito, Ximenes aponta que o "reconhecimento constitucional dos direitos fundamentais materializa-se na forma de princípios, caracterizados como 'mandamentos de otimização' do sistema jurídico” (XIMENES, 2014, p. 1048).

O direito à qualidade na educação básica é entendido, a partir do marco referencial desenvolvido com base na teoria dos direitos fundamentais como princípios de Alexy (2008) e nas disposiçóes normativas sobre o direito humano à educaçáo, como o conjunto de condiçóes de infraestrutura, humanas e de insumos que permitem o desenvolvimento de processos educacionais relevantes e adaptados, assegurados gratuita e universalmente pelo Estado, objetivando garantir a todos a aprendizagem de conteúdos e habilidades necessários à realização dos direitos humanos na educação e através da educação. O objetivo do direito à educação é alcançar a igualdade de base em termos de sucesso escolar, com respeito à diversidade, ou seja, maximizar também a realizaçáo destes princípios. [...] Complementa esse marco normativo 
sobre o conteúdo do princípio da qualidade da educação básica, ainda, a interação com os demais princípios do ensino inscritos no art. 206 da Constituição (XIMENES, 2014, p. 1048).

No Brasil, um resultado da recente instabilidade que coloca em risco esses princípios constitucionais para a educação é a aprovação da Emenda Constitucional no 95, de 2016 (BRASIL, 2016), que congela os investimentos públicos em educação por 20 anos, inviabilizando o Plano Nacional de Educação (Lei no 13.005/2014), conforme nota técnica da Campanha Nacional pelo Direito à Educação e da Associação Nacional de Pesquisadores em Financiamento da Educação (CAMPANHA NACIONAL PELO DIREITO À EDUCAÇÁO; FINEDUCA, 2016): "A aprovação da PEC 241 significa estrangular a educação pública brasileira e tornar letra morta o plano nacional de educação 2014-2024”, divulgada em 2016.

O conteúdo dessa nota integrou as denúncias feitas pela Campanha Nacional pelo Direito à Educação à Organização das Naçóes Unidas (ONU) em 2016, contribuindo para que os Relatores Especiais para a Erradicação da Pobreza e Educação se manifestassem, no dia 9 dezembro de 2016, com o comunicado Brasil: teto de 20 anos para o gasto público violará direitos humanos, alerta relator da ONU:

O Plano Nacional de Educação no Brasil clama pelo aumento de 37 bilhóes de reais anualmente para prover uma educação de qualidade para todos os estudantes, enquanto a Proposta de Emenda à Constituição (PEC) reduzirá o gasto planejado em 47 bilhóes de reais nos próximos oito anos. Com mais de 3,8 milhôes de crianças fora da escola, o Brasil não pode ignorar o direito deles de ir à escola, nem os direitos de todas as crianças a uma educação de qualidade (OHCHR, 2016).

O comunicado reconhece os impactos negativos da instabilidade política no Brasil. "O plano de mudar a Constituição para os próximos 20 anos vem de um governo que chegou ao poder depois de um impeachment e que, portanto, jamais apresentou seu programa a um eleitorado" (OHCHR, 2016). A Emenda Constitucional no 95 (BRASIL, 2016) vai na contramão da Lei do Plano Nacional de Educação (PNE, no 13.005/2014), que prevê, em sua meta 20 , progressivamente, o investimento de $10 \%$ do produto interno bruto (PIB) para a educação, incluindo em suas estratégias o Custo Aluno-Qualidade Inicial (CAQi), mecanismo de financiamento concebido pela sociedade civil brasileira no âmbito da Campanha Nacional pelo Direito à Educação que assegura um padrão mínimo de qualidade (BRASIL; 2014; CUSTO ALUNO-QUALIDADE INICIAL, 2018). 


\title{
Riscos com a abertura da Constituição e brechas para privatização da educação
}

\begin{abstract}
Conforme Ximenes (2014, p. 1032),
é em função do ecletismo e da abertura do texto constitucional que diferentes campos políticos se reconhecem como destinatários dos bens jurídicos ali protegidos e, portanto, exercem pressão legítima para a sua implementação, seja diretamente ou mediante regulamentação. Esse fenômeno ganha objetividade, por exemplo, nas disputas em torno da destinação dos recursos públicos para a educação, que opóem os movimentos em defesa da escola pública ao setor privado, organizado em suas entidades representativas, que buscam ampliar o repasse de recursos públicos para suas instituiçóes.
\end{abstract}

No caso da Guiné-Bissau, o incentivo à iniciativa privada e a uma regulação mercantil do sistema educativo está presente, contudo parece emergir certo paradoxo pois, se por um lado se incentiva a iniciativa privada, por outro se reconhece que parte da populaçáo, embora pague pela educação a que tem acesso, não tem capacidade financeira para tal (SILVA; SANTOS; PACHECO, 2015).

No Brasil, a denúncia da privatização da educação pública como violação do direto à educação foi pauta do Movimento dos Secundaristas em Ocupação durante o período de instabilidade e anúncio da Reforma do Ensino Médio de Temer e é preocupação da ONU, cujo Comitê sobre os Direitos da Criança recomenda "Encerrar a transferência de recursos públicos para o setor do ensino privado" (ONU, 2015). Privatização da educação pública é entendida, conforme Adrião e Domiciano (2018), como a natureza e a abrangência dos mecanismos de simbiose entre os setores privados e órgãos públicos que indicam a amplitude dos processos de privatização da educaçáo pública, entendida como o conjunto de processos que tem direcionado a educação básica pública brasileira para o campo e sob o interesse do setor privado corporativo ou associado a ele.

\section{Impactos da instabilidade a partir das vozes das "flores da revolução"}

Para falar de direito à educação é fundamental ouvir sujeitos de direito, no caso da educaçáo, os estudantes. As vozes aqui analisadas, tanto na Guiné-Bissau como no Brasil, confirmam os impactos negativos dos contextos de instabilidade (com transições não democráticas de governo). Assim como Amilcar Cabral valorizava as crianças as chamando de flores da revolução no período de 
libertação da Guiné-Bissau, vale registrar que as vozes analisadas nesse artigo são consideradas pelas suas autoras e autor como atuais flores da revolução pelo histórico de resistência.

Cá integrou a Rede de Crianças e Jovens Jornalistas da Guiné-Bissau (RCJJ) quando era adolescente, sendo essa a maior rede ativista infanto-juvenil de seu país. Os depoimentos dele aqui destacados são de entrevista realizada para a pesquisa de mestrado publicada em An Educommunication-based approach for the rights of the child. Responding to the challenge of implementing arlicle 12 of the CRC in Guinea-Bissau (REHDER, 2013). Letícia Karen participou de ativismo no movimento dos Secundaristas em Ocupação nas escolas públicas de São Paulo. As informações aqui destacadas são provenientes de artigo produzido com coautoria da estudante "Um olhar sobre a Educomunicação e alfabetização midiática. Das ondas do rádio do ensino fundamental ao ativismo no movimento dos secundaristas em ocupação" (REHDER \& OLIVEIRA, 2017).

Os dois textos acadêmicos de onde foram extraídos relatos desses estudantes destacam a importância do envolvimento de adolescentes em processos de educomunicação para a garantia do direito à participação e estímulo ao ativismo político para resistência. Participação, reconhecida como direito conforme o artigo 12 da Convenção sobre os Direitos da Criança (ONU, 1990), é aqui analisada a partir da perspectiva da educomunicação, compreendida como

o conjunto das açóes inerentes ao planejamento, implementação e avaliação de processos, programas e produtos destinados a criar e fortalecer ecossistemas comunicativos em espaços educativos presenciais ou virtuais, assim como a melhorar o coeficiente comunicativo das açóes educativas, incluindo as relacionadas ao uso dos recursos da informação no processo de aprendizagem (SOARES, 2002, p. 115).

Ecossistemas comunicativos seriam os processos que garantem essa participação, a partir de uma comunicação dialógica, horizontal, feita por jovens e para jovens. Na visão de Jesus Martín-Barbero, são "uma experiência cultural nova, ou como chamou Walter Benjamin, um sensorium novo. Novos modos de perceber e de sentir; uma nova sensibilidade que, em muitos aspectos, se choca e se rompe com o sensorium dos adultos" (MARTÍN-BARBERO, 2011, p. 125).

No entanto, pelo objetivo de reflexão comparada deste artigo e pela limitação de espaço, são priorizados trechos específicos da fala que confirmam os impactos da instabilidade no acesso à educação. Em resposta à primeira pergunta da entrevista realizada em 2013 "Como você descreve a vida de uma criança na Guiné-Bissau?”, o guineense Cá destaca os impactos da instabilidade política: 
Desde 1998, depois da guerra civil e depois da ratificação da Convençáo sobre os Direitos das Crianças, as organizaçóes estáo fazendo o seu melhor para melhorar a situaçáo, mas nem mesmos com esses esforços nós podemos enfrentar é possível o problema da educação hoje na Guiné-Bissau. Todas as escolas públicas estáo em greve neste momento, as crianças enfrentam problemas com práticas violentas e nós temos problemas tanto na educação como na saúde. Acredito que estes sejam as três áreas mais complicadas para as crianças (apud REHDER, 2013, p. 111).

A exclusão escolar gerada pelo trabalho infantil com as Campanhas de Caju, nos períodos de colheita, quando há migração das famílias que levam as crianças para trabalhar, e a infraestrutura escolar foram citadas pelo adolescente:

Não há água potável disponível para os estudantes na Guiné-Bissau. Não há banheiros. Sobre material, não usamos livros, mas os professores trabalham com o que chamamos de texto de apoio. Os professores levam o texto de apoio nas aulas e os estudantes copiam o material (REHDER, 2013, p. 111).

Os problemas relatados pelo adolescente estão em consonância com as preocupaçóes do Comitê sobre os Direitos da Criança da ONU. "O Comitê registra a crise política atual no Estado da Guiné-Bissau e seu efeito no desenvolvimento e implementação de legislação relevante, políticas públicas e programas para a infância” (ONU, 2015).

No Brasil, os impactos da instabilidade para a garantia do direito à educação foram confirmados pelo Movimento dos Secundaristas em Ocupação no Brasil, que teve início em 2015 com pautas locais, em São Paulo, marcado pela ocupação da gestão das escolas públicas por seus estudantes, mas que foi se intensificando nacionalmente em 2016 com a luta contra as medidas do governo Temer como a Reforma do Ensino Médio e, principalmente, a então Proposta de Emenda Constitucional (PEC 241 e PEC 55). No dia 25 de outubro de 2016, o El País Brasil destacou: "PEC 241: Com quase 1.000 escolas ocupadas no país, ato de estudantes chega a SP que uma das pautas nacionais majoritárias dos estudantes secundaristas em ocupação" (ROSSI, 2016).

$\mathrm{O}$ alerta dos relatores da ONU contra o congelamento dos gastos públicos para os setores sociais em 20 anos e a mobilização nacional dos estudantes por meio da ocupação das escolas públicas que ganharam as manchetes dos jornais, rádio, televisão e internet não impediram, porém, a aprovação da Emenda Constitucional no 95 (BRASIL, 2016). Entretanto, o levante dos Secundaristas em Ocupação representou um novo paradigma da participação e ativismo pelo direito à educação no Brasil, gerando inclusive demissóes de secretário estadual de educação, como no caso do estado de São Paulo. Na pauta 
de luta da adolescente Letícia Karen e dos mais de milhares de estudantes que ocuparam as escolas no Brasil, destacou-se a resistência contra as medidas do governo Temer.

Participar de todos os processos deste movimento que se tornou nacional, demonstrando a preocupação da juventude pelo ensino de qualidade me fez ter a certeza que somente a luta diária e as novas estratégias via ação e participação dentro das escolas podem resultar em conquistas positivas, afirma Letícia Karen. (REHDER \& OLIVEIRA, 2017, p. 543).

\section{Considerações finais}

O artigo buscou problematizar, em uma perspectiva comparada, os impactos da instabilidade política na Guiné-Bissau e no Brasil para implementação de suas constituiçôes, com ênfase no direito à educação, partindo de análise documental e das vozes de dois adolescentes.

Pôde-se constatar que a instabilidade política na Guiné-Bissau e no Brasil tem fragilizado a garantia dos princípios constitucionais para o direito à educação, impactando nos investimentos públicos alocados para os setores sociais e violando os direitos de crianças e adolescentes conforme confirmam os adolescentes.

No Brasil, destaca-se a Emenda Constitucional 95, inviabilizando o Plano Nacional de Educaçáo (Lei no 13.005/2014). Na Guiné-Bissau, alto porcentual do investimento proveniente da ajuda internacional que foi direcionado para governança e segurança em detrimento à saúde e à educação: menos de $1 \%$ do orçamento do Estado é alocado para as questóes das mulheres e das crianças e apenas 13\% para educação (ONU, 2013). Nos dois países, conclui-se que é urgente a ampliação dos investimentos para as áreas sociais por meio de estruturas de financiamento público que efetivem os direitos sociais. Conclusão também já alertada aos países por diferentes mecanismos de direitos humanos da ONU.

No Brasil, é urgente revogar a Emenda Constitucional no 95 a fim de viabilizar o Plano Nacional de Educaçáo, garantindo sua meta 20, resultado de histórica construçáo da sociedade civil no âmbito da Campanha Nacional pelo Direito à Educação, com o Custo Aluno-Qualidade Inicial —, mecanismo de cálculo do financiamento da educação pública que mostra o quanto deve ser investido ao ano por aluno de cada etapa e modalidade da educação básica, considerando os custos de manutenção das creches, pré-escolas e escolas para que esses equipamentos garantam padrão mínimo de qualidade conforme previsto na Constituição Federal de 1988 (CUSTO ALUNO-QUALIDADE INICIAL, 2018). 
$\mathrm{Na}$ Guiné-Bissau, a ampliação do montante proveniente da ajuda internacional alocado para educaçáo pelo governo é urgente. Seria interessante um aprofundamento, por meio de estudos, sobre o financiamento da educaçáo pública que permitam a análise sobre a aplicabilidade dos investimentos públicos por meio de estrutura de financiamento nos moldes do CAQi no Brasil.

Por fim, é comprovada a hipótese de que os impactos na realização do direito à educaçấo, devido à instabilidade política nos dois países, constituem indícios para maior aprofundamento e investigação posterior, a fim de contribuir para a produção acadêmica em educação e podendo constituir importante subsídio de resistência ante os retrocessos na Guiné-Bissau e no Brasil.

\section{Referências}

ADRIÂO, T.; DOMICIANO, C. A Educação Pública e as Corporaçôes: avanços e contradiçōes em uma década de ampliação de investimento no Brasil. FINEDUCA - Revista de Financiamento da Educą̧ão, Porto Alegre, v. 8, n. 3, p. 1-17, 2018. Disponível em: $<$ http://dx.doi.org/10.17648/fineduca-2236-5907-v8-79084>. Acesso em: 12 jul. 2018.

ARELARO, L.R.G. O ensino fundamental no Brasil: avanços, perplexidades e tendências. Educação \& Sociedade, Campinas, v. 26, n. 92, p. 1039-1066, out. 2005. Disponível em: <http://www.scielo.br/scielo.php?script=sci_arttext\&pid=S010173302005000300015\&lng=pt\&nrm=iso $>$. Acesso em: 12 jul. 2018.

BARRETO, A. Reformas recentes no sistema educativo da Guiné-Bissau: compromisso entre a identidade e a dependência. In: COLÓQUIO INTERNACIONAL CABO VERDE E GUINÉ-BISSAU: PERCURSOS DO SABER E DA CIÊNCIA, 2012, Lisboa. Atas... Lisboa: Instituto de Investigação Científica Tropical e Instituto Superior de Ciências Sociais e Políticas da Universidade Técnica de Lisboa. Disponível em: <https:// coloquiocvgb.files.wordpress.com/2013/06/p04c04-antc3b3nia-barreto.pdf $>$. Acesso em: 30 maio 2016.

BARROS, M. de. A Sociedade Civil face ao processo de democratizaçáo e desenvolvimento na Guiné Bissau (1991-2011). Africana Studia, n. 18, p. 71-82, 2012.

BARROS, M. de; RIVERA, O. A (re) construçao do estado no contexto dos estados fragéis: o caso da Guiné-Bissau. In: CONGRESSO INTERNACIONAL "ÁFRICAOCIDENTE” CORRESPONSABILIDAD EN EL DESARROLLO, 2., 2011, Huelva. Anais... Huelva: Fundación Europea para la Cooperación Norte-Sur FECONS. v. 2. p. 603-619.

BRASIL. Constituição da República Federativa do Brasil. Brasília: Senado Federal, 1988.

Emenda Constitucional no 95. Altera o Ato das Disposiçôes Constitucionais Transitórias, para instituir o Novo Regime Fiscal, e dá outras providências. Brasília: Senado Federal, 2016.

Lei no 13.005, de 25 de junho de 2014. Aprova o Plano Nacional de EducaçáoPNE e dá outras providências. Diário Oficial da União, 2014. 
BRITISH EDUCATIONAL RESEARCH ASSOCIATION (BERA). Ethical Guidelines for Educational Research. Londres: BERA, 2011. Disponível em: <https://www.bera. ac.uk/wp-content/uploads/2014/02/BERA-Ethical-Guidelines-2011.pdf>. Acesso em: 30 maio 2016.

CÁ, L.O. A constituição da politica do currículo na Guiné-Bissau e o mundo globalizado. Cuiabá: Editora da Universidade Federal de Mato Grosso/CAPES, 2008.

CAMPANHA NACIONAL PELO DIREITO À EDUCAÇÃO; ASSOCIAÇÃO NACIONAL DE PESQUISA EM FINANCIAMENTO DA EDUCAÇÃO (FINEDUCA). A aprovação da PEC 241 significa estrangular a educação pública brasileira e tornar letra morta o Plano Nacional de Educação 2014-2024 - Nota conjunta. 2016. Disponível em: <http://www.fineduca.org.br/wp-content/uploads/2016/10/Notaconjunta-FINEDUCA-CNDE 01 2016.pdf $>$. Acesso em: 12 jul. 2018.

CARRANO, P. Um "novo" ensino médio é imposto aos jovens no Brasil. Associação Nacional de Pós-Graduação e Pesquisa Educacional, 2017. Disponível em: <http://www. anped.org.br/news/um-novo-ensino-medio-e-imposto-aos-jovens-no-brasil>. Acesso em: 12 jul. 2018.

CARR-HILL, R.; ROSENGART, G. Education in Guinea-Bissau 1978-81: the impact of Swedish assistance: an evaluation made jointly by the Ministry of National Education, Bissau, and SIDA. n. 5. Estocolmo: SIDA, Divisão Educacional, 1982.

CARR-HILL, R.; ROSENGART, G. Education since independence in Guinea-Bissau. International Journal of Educational Development, v. 3, n. 3, p. 325-336, 1983. https://doi. org/10.1016/0738-0593(83)90051-2

CENTRAL INTELIGENCE AGENCY (CIA). The Wold Factbook. Guinea-Bissau, 2018. Disponível em: <https://www.cia.gov/library/publications/the-world-factbook/geos/ pu.html>. Acesso em: 30 maio 2018.

CHABAL, P. Amilcar Cabral Revolutionary leadership and people's war. Londres: Hurst \& Company, 2002.

COHEN, L.; MANION, L.; MORRISON, K. Research Methods in Education. Nova York: Routledge, 2009.

CROSSLEY, M.; WATSON, K. Comparative and International Educational Research in Education - Globalisation, context and difference. Londres: Routledge Falmer, 2003.

CURY, C.R.J. A educação básica como direito. Cadernos de Pesquisa, São Paulo, v. 38, n. 134, p. 293-303, ago. 2008. Disponivel em: <http://www.scielo.br/scielo. php? script $=$ sci arttext\&pid $=S 0100-15742008000200002 \& \operatorname{lng}=$ en \&nrm=iso $>$. Acesso em: 12 jul. 2018. http://dx.doi.org/10.1590/S0100-15742008000200002

CUSTO ALUNO-QUALIDADE INICIAL (CAQi). In: CAMPANHA NACIONAL PELO DIREITO À EDUCAÇÃO. 2018. Disponível em: <www.custoalunoqualidade. org.br>. Acesso em: 30 maio 2018.

FREIRE, P. Cartas à Guiné-Bissau: registros de uma experiência em processo. Rio de janeiro: Paz e Terra, 1977. 
FUNDO DAS NAÇÕES UNIDAS PARA A INFÂNCIA (UNICEF). Out of School Children in Guinea Bissau: Inception Report. Bissau: UNICEF, 2018.

FURTADO, A.B.R. Administração e Gestão da Educação na Guiné-Bissau. Tese (Doutorado em Educação) - Departamento de Ciências da Educação, Universidade de Aveiro, Aveiro, 2005.

GADOTTI, M.; ROMÃO, J.E. Paulo Freire e Amílcar Cabral: a descolonização das mentes. São Paulo: Instituto Paulo Freire, 2012.

GUINÉ-BISSAU. Constituição da República da Guiné-Bissau. Bissau: Assembleia Nacional Popular, 1996.

Lei no 4/2011. Lei de Bases do Sistema Educativo (2011). Boletim Oficial, Bissau, n. 13, p.2 9-40, 29 mar. 2011 a.

- Ministério da Educação Nacional, Ciência, Cultura, Juventude e Desportos (MENCCJD). Pedido Financeiro ao Fundo da Parceria Global para a Educação. Bissau, $2011 b$.

MARTÍN-BARBERO, J. Desafios culturais: da comunicação à educomunicação. In: CITELLI, A.O. \& COSTA, M.C.C. (Orgs.) Educomunicação: construindo uma nova área de conhecimento. São Paulo: Paulinas, 2011. p. 121-134.

MENDES, P.R. Guiné-Bissau: Respostas de paz à impunidade e exclusão. Bruxelas, 2013. Disponível em: <http://eplo.org/wp-content/uploads/2017/02/EPLO BackgroundPaper Guinea-Bissau PT.pdf >. Acesso em: 30 maio 2018.

MO IBRAHIM FOUNDATION. Ibrabim Index of African Governance: Country Insights - Guinea-Bissau. 2017. Disponível em: <http://mo.ibrahim.foundation/ iiag/2017-key-findings/>. Acesso em: 30 maio 2018.

MONTEIRO, J. A Educação na Guiné Bissau: Bases para uma estratégia sectorial renovada. Bissau, 2005.

OFFICE OF THE UNITED NATIONS HIGH COMMISSIONER FOR HUMAN RIGHTS (OHCHR). Brasil: Teto de 20 anos para o gasto público violará direitos humanos, alerta relator da ONU. Office of the United Nations High Commissioner for Human Rights, 2016. Disponível em: <http:/www.ohchr.org/EN/NewsEvents/Pages/ DisplayNews.aspx?NewsID=21006>. Acesso em: 30 maio 2018.

O'REGAN, D.; THOMPSON, P. Advancing Stability and Reconciliation in GuineaBissau: Lessons from Africa's First Narco-State. Africa Center for Strategies Studies, Washington, D.C., n. 2, 2013. Disponível em: <http://africacenter.org/wp-content/ uploads/2013/06/SpecialReport-Guinea-Bissau-JUN2013-EN.pdf $>$. Acesso em: 30 maio 2018.

ORGANIZAÇÃO DAS NAÇÓES UNIDAS (ONU). Concluding observations on the combined second to fourth periodic reports of Brazil. ONU, 2015.

. Concluding observations on the combined second to fourth periodic reports of Guinea-

Bissau, adopted by the Committee at its sixty-third session (27 May-14 June 2013). ONU, 2013. 
ORGANIZAÇÃO DAS NAÇÓES UNIDAS PARA A EDUCAÇÃO, A CIÊNCIA E A CULTURA (UNESCO). Em Guiné-Bissau, o sistema educativo precisa em grande parte de ser construido. UNESCO, 2016. Disponível em: <http://unesdoc.unesco.org/ images/0024/002470/247043POR.pdf>. Acesso em: 30 maio 2018.

. Guiné-Bissau - Relatório da Situação do Sistema Educativo. Margens de manobra para o desenvolvimento do sistema educativo numa perspectiva de universalização do Ensino Básico e de redução da pobreza. Dacar, 2013.

PEHRSSON, K. O direito à educação na Guiné-Bissau: análise genérica dos problemas do sector. Bissau, 1996.

PHILLIPS, D.; SCHWEISFURTH, M. Comparative and International Education: An Introduction to Theory, Method, and Practice. Londres: Bloomsbury Academic, 2014.

REHDER, M.C.G. An Educommunication-based approach for the rights of the child. Responding to the challenge of implementing arlicle 12 of the CRC in Guinea-Bissau. Dissertação (Mestrado) - Escola de Economia e Ciência Política, Universidade de Pádua, Pádua, 2013.

REHDER, M.C.G.; OLIVEIRA, L.K. Um olhar sobre a Educomunicação e alfabetização midiática. Das ondas do rádio do ensino fundamental ao ativismo no movimento dos secundaristas em ocupação. In: SOARES, I.O.; VIANA, C.E.; XAVIER, J.B. (Orgs.). Educomunicação e suas áreas de intervenção: novos paradigmas para o diálogo intercultural. São Paulo: ABPEducom, 2017. p. 539-540.

ROBSON, C. Real world research: a resource for social scientists and practitionerresearchers. Chichester: Wiley, 2011.

ROSSI, M. PEC 241: Com quase 1.000 escolas ocupadas no país, ato de estudantes chega a SP que uma das pautas nacionais majoritárias dos estudantes secundaristas em ocupação. El País Brasil, São Paulo, 25 out. 2016. Disponível em: <https://brasil.elpais.com/ brasil/2016/10/24/politica/1477327658 698523.html>. Acesso em: 30 de maio de 2018.

SILVA, R. da; SANTOS, J.G.; PACHECO, J.A. Crossed looks: globalisations and curriculum in Guinea-Bissau. Compare: A Journal of Comparative and International Education, v 45, n. 6 , p. 978-999, 2015. https://doi.org/10.1080/03057925.2015.1013018

SOARES, I.O. Gestão comunicativa e educação: caminhos da educomunicação. Comunicação \& Educação, São Paulo, n. 23, p. 16-25, 2002. Disponível em: <http:// dx.doi.org/10.11606/issn.2316-9125.v0i23p16-25>. Acesso em: 30 maio 2018.

SOUSA, J.S. Guiné-Bissau: a destruição de um país: desafios e reflexôes para uma nova estratégia nacional. Coimbra: Coimbra Editora, 2012.

TEMUDO, M.; ABRANTES, M. Changing policies, shifting livelihoods: The fate of agriculture in Guinea-Bissau. Journal of Agrarian Change, v. 13, n. 4, p. 571-589, 2013. https://doi.org/10.1111/j.1471-0366.2012.00364.x

TEMUDO, M.; ABRANTES, M. The Pen and the Plough: Balanta Young Men in Guinea-Bissau. Development and Change, v. 46, n. 3, p. 464-485, 2015. https://doi. org/10.1111/dech.12166 
TEMUDO, M.P. From "people's struggle" to "this war of today": entanglements of peace and conflict in Guinea-Bissau. Africa: Journal of the International African Institute, v. 78, n. 2, p. 245-263, 2008. https://doi.org/10.1353/afr.0.0016

UNICEF. A Convenção sobre os Direitos da Criança. Adotada pela Assembléia Geral nas Naçóes Unidas em 20 de novembro (1989). Disponível em: https://www.unicef.org/ brazil/pt/resources 10120.html. Consulta em: 30 de maio de 2018.

XIMENES, S.B. O Conteúdo Jurídico do Princípio Constitucional da Garantia de Padrão de Qualidade do Ensino: uma contribuição desde a teoria dos direitos fundamentais. Educação \& Sociedade, Campinas, v. 35, n. 129, p. 1027-1051, dez. 2014. Disponível em: <http://www.scielo.br/scielo.php?script=sci_arttext\&pid=S010173302014000401027\&lng=pt\&nrm=iso $>$. Acesso em: 12 jul. 2018. http://dx.doi. org/10.1590/ES0101-73302014143815

Recebido em $1^{\circ}$ de junho de 2018.

Aceito em 22 de agosto de 2018. 